\title{
Erratum to: Inpatient Enteral and Parental Nutrition for Patients with Diabetes
}

\author{
Michael A. Via • Jeffrey I. Mechanick
}

Published online: 12 March 2011

(C) Springer Science+Business Media, LLC 2011

Erratum to: Curr Diab Rep (2011) 11:99-105

DOI 10.1007/s11892-010-0168-5

The original version of this article published in Current Diabetes Reports, Volume 11, Issue 2, April 2011, unfortunately contained an error in the article title. The word Parental should have been listed as "Parenteral." The correct title should be "Inpatient Enteral and Parenteral Nutrition for Patients with Diabetes."

The online version of the original article can be found at http://dx.doi. org/10.1007/s11892-010-0168-5.

M. A. Via $(\bowtie)$

Division of Endocrinology and Metabolism, Beth Israel Medical

Center, Albert Einstein College of Medicine,

55 East 34th Street,

New York, NY 10016, USA

e-mail: mvia@chpnet.org

J. I. Mechanick

Metabolic Support, Division of Endocrinology, Diabetes, and

Bone Disease, Mount Sinai School of Medicine,

New York, NY, USA 